\title{
Prevention of Vascular Dysfunction after Preeclampsia: A Potential Long-Term Outcome Measure and an Emerging Goal for Treatment
}

\author{
Merzaka Lazdam, ${ }^{1}$ Esther F. Davis, ${ }^{1}$ Adam J. Lewandowski, ${ }^{1}$ Stephanie A. Worton, ${ }^{2}$ \\ Yvonne Kenworthy, ${ }^{1}$ Brenda Kelly, ${ }^{2}$ and Paul Leeson ${ }^{1}$ \\ ${ }^{1}$ Department of Cardiovascular Medicine, Oxford Cardiovascular Clinical Research Facility, University of Oxford, \\ John Radcliffe Hospital, Oxford OX3 9DU, UK \\ ${ }^{2}$ Department of Obstetrics and Gynaecology, University of Oxford, John Radcliffe Hospital, Oxford OX3 9DU, UK
}

Correspondence should be addressed to Paul Leeson, paul.leeson@cardiov.ox.ac.uk

Received 29 July 2011; Accepted 15 September 2011

Academic Editor: Christos Iavazzo

Copyright ( $) 2012$ Merzaka Lazdam et al. This is an open access article distributed under the Creative Commons Attribution License, which permits unrestricted use, distribution, and reproduction in any medium, provided the original work is properly cited.

\begin{abstract}
Preeclampsia is increasingly being recognised as more than an isolated disease of pregnancy. In particular, preeclampsia has emerged as an independent risk factor for maternal cardiovascular disease and has recently been recognised as a risk factor for cardiovascular disease in children exposed in utero. Preeclampsia and cardiovascular disease may share important pathophysiological and molecular mechanisms and further investigation into these is likely to offer insight into the origins of both conditions. This paper considers the links between cardiovascular disease and preeclampsia and the implication of these findings for refinement of the management of patients whose care is complicated by preeclampsia.
\end{abstract}

\section{Introduction}

Although traditionally preeclampsia has been viewed as a condition that resolves completely with the delivery of the placenta, there is now increasing evidence that preeclampsia may constitute a condition with significant long-term health implications for both the mother and child. In particular preeclampsia has recently emerged as an independent risk factor for maternal cardiovascular disease 10-15 years after the index pregnancy [1-3]. A history of preeclampsia is therefore now considered a relevant factor in the cardiovascular risk assessment in women [4] and is associated with an increase in risk similar in magnitude to a history of dyslipidemia [5]. Meta-analysis has demonstrated that in the 10-15 years following a preeclamptic pregnancy women have an increased risk of developing hypertension (RR $3.795 \%$ C.I. $(2.7-5.05, P<0.001)$ ), coronary artery disease (RR 2.16 95\% C.I. $(1.86-2.52, P=0.001)$ ), and stroke (RR $1.8195 \%$
C.I. (1.45-2.27, $P=0.00)$ [1]. Additionally, it has been demonstrated that there is a graded relationship between the risk of cardiac disease and the severity of preeclampsia with maternal risk being greatest with early onset or severe preeclampsia [6]. Children born to preeclamptic women have also been demonstrated to have elevated blood pressure in childhood and adolescence [7-12].

This highlights potentially important pathophysiological or molecular links between preeclampsia and cardiovascular disease. Greater insight into these links may identify new opportunities to understand disease predisposition and treatment and may also raise the possibility that prevention of vascular dysfunction should be an important long-term goal of preeclampsia management. This paper will consider the current literature considering the links between cardiovascular disease and preeclampsia and the implication of these findings for refining the management of patients whose care is complicated by preeclampsia. 


\section{What Links Preeclampsia and Cardiovascular Disease?}

The aetiology of preeclampsia remains incompletely understood, though disturbed placentation and placental functioning in early pregnancy remains the leading hypothesis [31]. During normal placental development, fetal cytotrophoblasts invade the maternal spiral arteries transforming them to high-caliber capacitance vessels providing low resistance placental perfusion adequate to sustain fetal growth [32]. However, inadequate spiral artery remodeling in preeclampsia is thought to lead to chronic placental ischaemia or intermittent flow through the narrow muscular arteries thereby creating an ischaemia-reperfusion phenomenon [33].

Reactive oxygen species and cytokines released from the ischaemic placenta trigger a systemic oxidative stress [34] and contribute to the exaggerated systemic inflammatory reaction in preeclampsia $[33,35]$. Syncytiotrophoblasts undergoing apoptosis also shed increased numbers of microparticles in the maternal circulation which contribute to this process. The release of cytokines and acute phase proteins, such as $\mathrm{TNF} \alpha$, leptin, and PAI-1, not only enhance the inflammatory response but also induce some of the observed metabolic disturbances in preeclampsia including insulin resistance, lipolysis, and hyperlipidaemia [33, 34].

Furthermore, hypoxic oxidative stress and inflammatory stimuli provoke the release of antiangiogenic factors (via NF- $\kappa$ B pathways) $[33,36-38]$. Soluble Fms-Like Tyrosine kinase-1 (sFLT-1), a circulating truncated form of VEGF receptor, binds and reduces levels of VEGF and PlGF in the maternal circulation thereby inhibiting angiogenesis and vasodilatation [39]. This aberrant vasculature is thought to lead to a cascade of events which end in symptomatic systemic endothelial dysfunction [40]. Soluble endoglin, a TGF- $\beta$ coreceptor, is one of the antiangiogenic factors that enhances vascular permeability and may possibly affect nitric oxide synthesis and vasodilatation via altered downstream signalling in the TGF- $\beta$ pathway contributing to the endothelial dysfunction [35] (Figure 1).

Consistent with these biological changes, reduced endothelial-dependent vasodilatation in conduit and resistance arteries [21, 41-47] has been demonstrated in women who have preeclampsia. They also appear to have increased arterial stiffness [13], increased atherosclerosis [48], and diminished capillary density [49]. Biochemical markers of endothelial activation and dysfunction are also elevated in preeclampsia $[34,50]$. Maternal endothelial dysfunction is also present in conduit vessels before the onset of clinical disease [42] and up to three years after an affected pregnancy $[24,51,52]$. The increase in cardiovascular risk following preeclampsia may be a consequence of the pro-atherogenic impact of persistent endothelial dysfunction, a result of subclinical endothelial injury at the time of pregnancy, or to preexisting differences in endothelial function that predispose to both conditions (Figure 2).

Dysfunction of the vascular endothelium is a key factor in the development of atherosclerotic cardiovascular disease and has been demonstrated to precede clinically identifiable structural changes in the vasculature [53]. Peripheral dysfunction of the vascular endothelium has been demonstrated to correlate with increased risk of clinical events [54] and all cause mortality [55] and associates with many traditional cardiovascular risk factors including hypertension, diabetes mellitus, insulin resistance, hypercholesterolemia, and smoking [56]. In addition to this, endothelial dysfunction has been demonstrated in young adults predisposed to hypertension without clinical evidence of arterial disease [57]. Endothelial health and nitric oxide synthase activity are crucial in modulating arterial distensibility [58-60] and carotid intima media thickness $[61,62]$ independent of risk factors [62] as well as myocardial hypertrophic responses in animals [6365]. Left ventricular mass, another powerful independent predictor of mortality and morbidity in adults free of clinical disease [66], has a graded relationship with vascular endothelial vasomotor responses in hypertensive adults [67-72]. The strong relationship between endothelial dysfunction and cardiovascular outcomes and risk factors make it an interesting pathophysiological endpoint in the evaluation of therapies designed to modify long-term cardiovascular risk.

\section{Maternal Vascular Function as an Intermediate Endpoint in the Management of Preeclampsia}

As women who have experienced preeclampsia constitute a relatively young group, and there is potentially a prolonged period between exposure and clinical outcome, intermediate measures which may indicate a potentially modifiable change in risk are of particular value. Noninvasive measures of vascular function are widely used as surrogate markers of cardiovascular risk $[73,74]$. For example, increasing arterial stiffness, demonstrated by an increase in pulse wave velocity, is an antecedent factor in elevated blood pressure, predicts the future cardiovascular risk of adults, and correlates strongly with the presence of atherosclerosis [75]. Similarly, early evidence of atherosclerosis demonstrated by increased thickness of the arterial wall is correlated with coronary artery disease and is predictive of future infarction and stroke $[75,76]$. Changes in these parameters may therefore also offer unique insight into the cardiovascular risk of women and children following a preeclamptic pregnancy.

Several relatively small-scale studies have also demonstrated vascular dysfunction after pregnancy complicated by preeclampsia with evidence of endothelial dysfunction in the macrocirculation $[14,16,18,22-24,26]$ up to a median of 3 years and the microcirculation up to 25 years later $[15,27$, $30]$, as well as increased arterial stiffness [13,14, 16, 17] up to almost 5 years after the index pregnancy and atherosclerosis over 3 months postpartum [19]. Elevation of systemic biomarkers of endothelial injury and inflammation have also been described between 6 weeks [77] and 20 years [78-80] following preeclampsia. The characteristics and results of current literature considering the impact of preeclampsia on vascular structure and function are summarised in Table 1. There is, however, some disparity in results with some studies demonstrating no change in vascular function following 


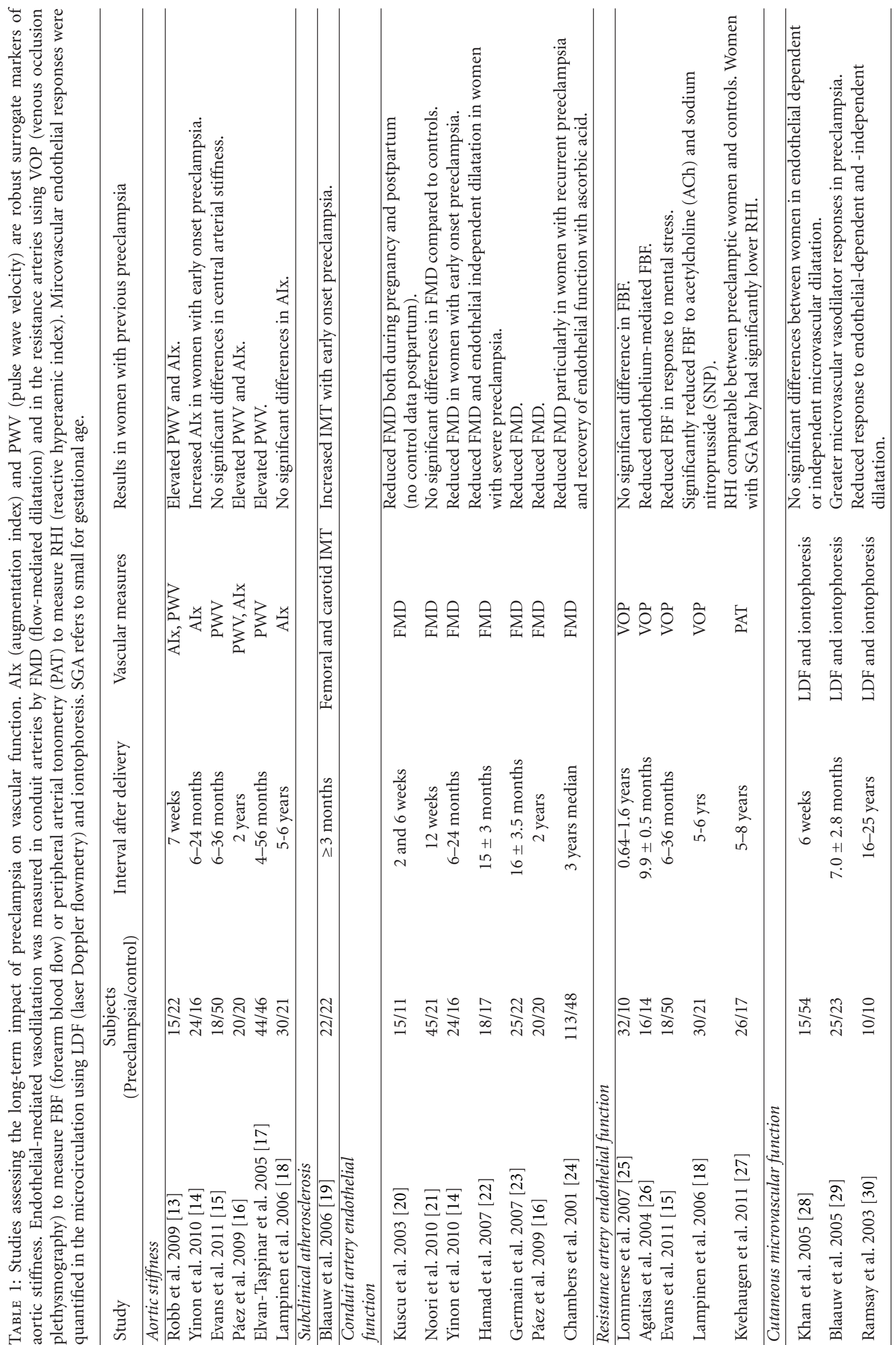




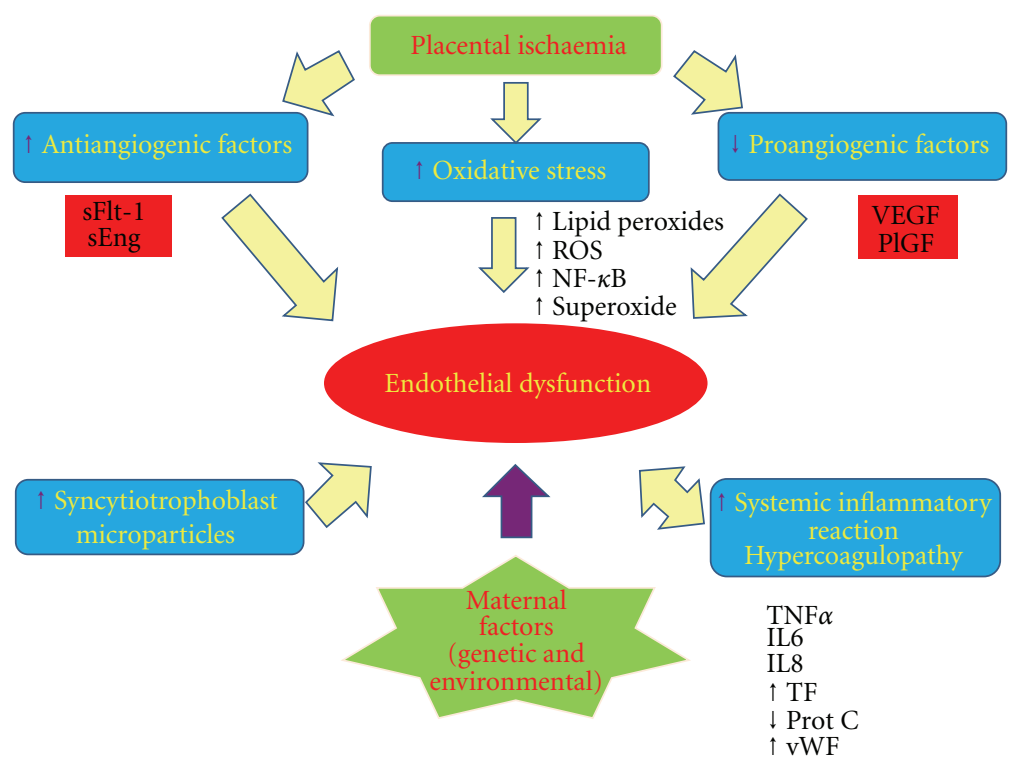

Figure 1: Molecular and vascular mechanisms of endothelial dysfunction in preeclampsia. Defective placentation, a common feature of preeclampsia, triggers a cascade of events including oxidative stress and exaggerated inflammatory reaction and angiogenic imbalance which exacerbate endothelial dysfunction. Impaired endothelial function plays a central role in the clinical manifestations of preeclampsia such as hypertension and proteinuria.

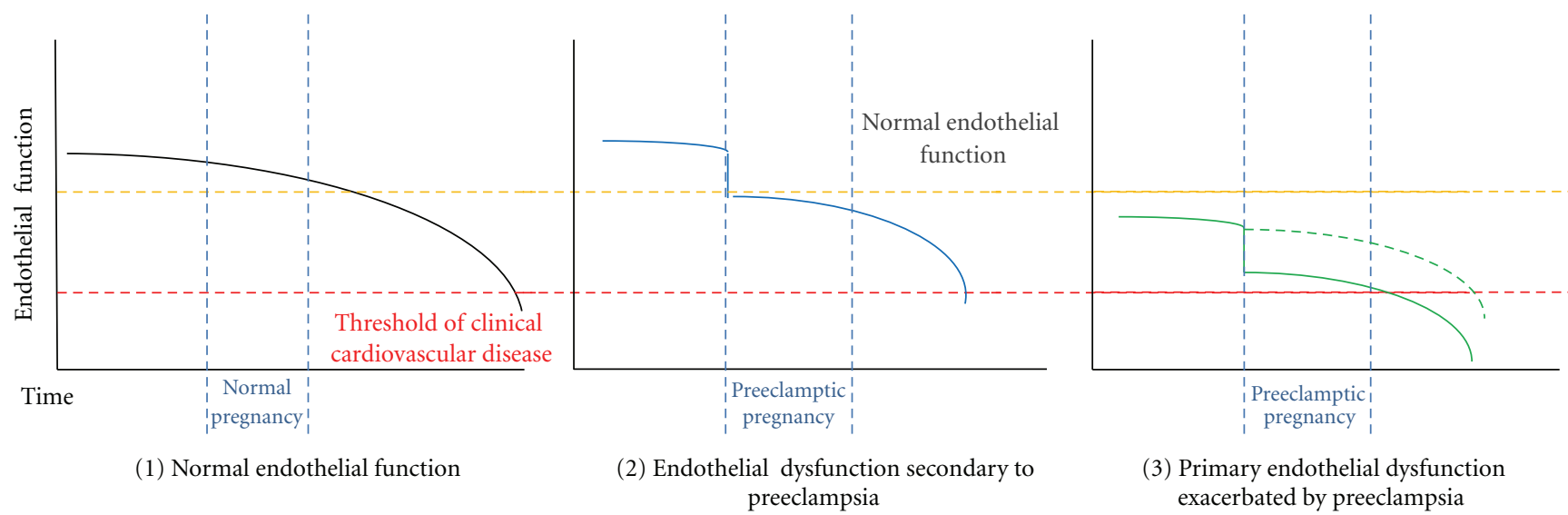

Figure 2: Theoretical timelines of impairment of endothelial function and development of cardiovascular disease following preeclamptic pregnancy. (1) In the normal individuals there is a gradual age-related reduction in endothelial function, which can be exacerbated by the presence of cardiovascular risk factors and associates with the future risk of clinical cardiovascular disease. (2) Women who experience preeclamptic pregnancies are known to have impaired endothelial function during pregnancy and up to 3 years following an affected pregnancy. It is possible that these women begin life with normal endothelial function, which is acutely impaired during a preeclamptic pregnancy. This followed by ongoing age-related decreases in endothelial function may relate to the increased incidence of cardiovascular disease in these individuals. (3) Alternatively, women who develop preeclampsia may have primary endothelial dysfunction which both puts them at risk of preeclampsia, this may then be exacerbated by the preeclamptic pregnancy (solid line), or simply persist (dotted line), in either case leading to higher incidence of cardiovascular disease.

preeclampsia $[21,25,28,81]$. This may in part reflect heterogeneity in patient cohorts, severity of preeclampsia, size of cohorts, the timing of the studies following the affected pregnancy, as well as differences in the vascular beds studied and the techniques employed. In the future more detailed long-term follow-up studies of such women may clarify changes in cardiovascular physiology and inform future treatment.

\section{Offspring Vascular Function Following Preeclampsia}

Even more than their mothers, children born following a preeclamptic pregnancy, constitute a cohort where early life preventative strategies may have a profound impact on future cardiovascular risk. Furthermore, adults whose mothers had preeclampsia themselves have a higher risk 
of the condition. Therefore, in this group evidence of subtle changes in vascular physiology indicating changes in risk are of particular importance. The body of literature considering cardiovascular outcomes in the offspring of preeclamptic pregnancies is sparse when compared to that considering maternal health. A single 60-year-follow-up study of individuals born to preeclamptic women demonstrated an increased risk of stroke in later life (RR 1.9 95\% C.I. $(1.2-3.0, P=0.01)$ ) [82]. Offspring of hypertensive pregnancies have also been shown to have an increased risk of hypertension as adults $[82,83]$ as well as having increased, although not pathological, blood pressure in childhood and adolescence [84]. Meta-analysis suggests that the magnitude of this increase in young individuals for systolic blood pressure is $2.3 \mathrm{mmHg}$ and for diastolic blood pressure is $1.7 \mathrm{mmHg}$ [84]. Although such increases are unlikely to be clinically recognisable, it may have significant public health significance as a $2 \mathrm{mmHg}$ rise in systolic blood pressure has been associated with a $7 \%$ increase in ischaemic heart disease mortality and a $10 \%$ increase in stroke [85].

Preterm offspring born to hypertensive pregnancies demonstrate a distinct cardiovascular phenotype, characterised by reduced conduit artery endothelial function and increased evidence of early atherosclerosis, compared to individuals born preterm to normotensive women [7]. A finding which has now been replicated in other groups $[27,86,87]$ and may be similar to the vascular dysfunction seen in women following preeclamptic pregnancies [27]. Although the underlying mechanisms remain unknown, there is substantial evidence of "programming" of aspects of vascular biology during fetal development, in particular en-dothelial responses [88] and arterial stiffness [89]. The risk to the offspring is likely to be mediated through changes in maternal blood pressure, vascular resistance in the placenta, or exposure to maternal factors (such as antiangiogenic factors [90], vasoactive substances [91], and reactive oxygen species) in the fetomaternal circulation. Optimal management of preeclampsia may have indirect benefits to reduce cardiovascular risk in the offspring of such pregnancies [92]. Hence, better understanding of the long-term vascular changes in offspring of preeclampsia may allow assessment of novel and previously unrecognised long-term outcomes of preeclampsia with important public health significance.

\section{Conclusions and Future Directions}

It is now becoming clear that preeclampsia is more than an isolated disease of pregnancy. The long-term health implications of this condition for both the women and their children are increasingly being recognised and incorporated into clinical risk assessments [4]. Both women and children exposed to preeclampsia exhibit an adverse vascular phenotype, a propensity to subclinical atherosclerosis, and increased risk of adverse cardiac and vascular events in future life. As preeclampsia affects $2-5 \%$ of the population this altered risk is relevant to the health of 1.2 to 3 million people in the UK and 6 to 15 million people in the USA. Optimal management of preeclampsia may be able to improve short and long-term vascular outcomes in these individuals. While we remain unable to effectively prevent preeclampsia attempts to reduce its long-term impact on those exposed are of potential importance. Future studies that define the detailed cardiovascular phenotype of those exposed to preeclampsia may allow identification of potential targets for future preventative strategies. Furthermore, studies into the mechanisms underlying the altered cardiovascular phenotype may provide unique insight into pathophysiological or molecular links between preeclampsia and cardiovascular disease, which may direct us to novel treatment strategies for both conditions. Vascular dysfunction is an early marker of cardiovascular risk, correlating with future risk of cardiac events and preceding structural vascular change [53]. Improvement in vascular function would therefore be a valuable intermediate endpoint in studies aiming to reduce risk in this potentially young and generally asymptomatic population before the onset of clinical disease.

\section{References}

[1] L. Bellamy, J. P. Casas, A. D. Hingorani, and D. J. Williams, "Pre-eclampsia and risk of cardiovascular disease and cancer in later life: systematic review and meta-analysis," British Medical Journal, vol. 335, no. 7627, pp. 974-977, 2007.

[2] S. D. McDonald, A. Malinowski, Q. Zhou, S. Yusuf, and P. J. Devereaux, "Cardiovascular sequelae of preeclampsia/eclampsia: a systematic review and meta-analyses," American Heart Journal, vol. 156, no. 5, pp. 918-930, 2008.

[3] J. A. Lykke, J. Langhoff-Roos, B. M. Sibai, E. F. Funai, E. W. Triche, and M. J. Paidas, "Hypertensive pregnancy disorders and subsequent cardiovascular morbidity and type 2 diabetes mellitus in the mother," Hypertension, vol. 53, no. 6, pp. 944951, 2009.

[4] L. Mosca, E. J. Benjamin, K. Berra et al., "Effectiveness-based guidelines for the prevention of cardiovascular disease in women-2011 update: a Guideline from the American Heart Association," Circulation, vol. 123, no. 11, pp. 1243-1262, 2011.

[5] L. A. Magee and P. von Dadelszen, "Pre-eclampsia and increased cardiovascular risk," British Medical Journal, vol. 335, no. 7627, pp. 945-946, 2007.

[6] H. U. Irgens, L. Reisæter, L. M. Irgens, and R. T. Lie, "Long term mortality of mothers and fathers after pre-eclampsia: population based cohort study," British Medical Journal, vol. 323, no. 7323, pp. 1213-1217, 2001.

[7] M. Lazdam, A. De La Horra, A. Pitcher et al., "Elevated blood pressure in offspring born premature to hypertensive pregnancy: is endothelial dysfunction the underlying vascular mechanism?" Hypertension, vol. 56, no. 1, pp. 159-165, 2010.

[8] M. Higgins, J. Keller, and F. Moore, "Studies of blood pressure in Tecumseh, Michigan. I. Blood pressure in young people and its relationship to personal and familial characteristics and complications of pregnancy in mothers," The American Journal of Epidemiology, vol. 111, no. 2, pp. 142-155, 1980.

[9] H. G. Langford and R. L. Watson, "Prepregnant blood pressure, hypertension during pregnancy, and later blood pressure of mothers and offspring," Hypertension, vol. 2, no. 4, pp. 130133,1980 .

[10] H. Palti and E. Rothschild, "Blood pressure and growth at 6 years of age among offsprings of mothers with hypertension 
of pregnancy," Early Human Development, vol. 19, no. 4, pp. 263-269, 1989.

[11] D. S. Seidman, A. Laor, R. Gale, D. K. Stevenson, S. Mashiach, and Y. L. Danon, "Pre-eclampsia and offspring's blood pressure, cognitive ability and physical development at 17-yearsof-age," British Journal of Obstetrics \& Gynaecology, vol. 98, no. 10, pp. 1009-1014, 1991.

[12] S. Tenhola, E. Rahiala, P. Halonen, E. Vanninen, and R. Voutilainen, "Maternal preeclampsia predicts elevated blood pressure in 12-year-old children: evaluation by ambulatory blood pressure monitoring," Pediatric Research, vol. 59, no. 2, pp. 320-324, 2006.

[13] A. O. Robb, N. L. Mills, J. N. Din et al., "Influence of the menstrual cycle, pregnancy, and preeclampsia on arterial stiffness," Hypertension, vol. 53, no. 6, pp. 952-958, 2009.

[14] Y. Yinon, J. C. P. Kingdom, A. Odutayo et al., "Vascular dysfunction in women with a history of preeclampsia and intrauterine growth restriction: insights into future vascular risk," Circulation, vol. 122, no. 18, pp. 1846-1853, 2010.

[15] C. S. Evans, L. Gooch, D. Flotta et al., "Cardiovascular system during the postpartum state in women with a history of preeclampsia," Hypertension, vol. 58, no. 1, pp. 57-62, 2011.

[16] O. Páez, J. Alfie, M. Gorosito et al., "Parallel decrease in arterial distensibility and in endothelium-dependent dilatation in young women with a history of pre-eclampsia," Clinical and Experimental Hypertension, vol. 31, no. 7, pp. 544-552, 2009.

[17] A. Elvan-Taşpinar, M. L. Bots, A. Franx, H. W. Bruinse, and R. H. H. Engelbert, "Stiffness of the arterial wall, joints and skin in women with a history of pre-eclampsia," Journal of Hypertension, vol. 23, no. 1, pp. 147-151, 2005.

[18] K. H. Lampinen, M. Rönnback, R. J. Kaaja, and P. H. Groop, "Impaired vascular dilatation in women with a history of preeclampsia," Journal of Hypertension, vol. 24, no. 4, pp. 751-756, 2006.

[19] J. Blaauw, M. G. van Pampus, J. J. van Doormaal et al., "Increased intima-media thickness after early-onset preeclampsia," Obstetrics and Gynecology, vol. 107, no. 6, pp. 13451351, 2006.

[20] N. K. Kuscu, Z. Kurhan, Y. Yildirim, T. Tavli, and F. Koyuncu, "Detection of endothelial dysfunction in preeclamptic patients by using color Doppler sonography," Archives of Gynecology and Obstetrics, vol. 268, no. 2, pp. 113-116, 2003.

[21] M. Noori, A. E. Donald, A. Angelakopoulou, A. D. Hingorani, and D. J. Williams, "Prospective study of placental angiogenic factors and maternal vascular function before and after preeclampsia and gestational hypertension," Circulation, vol. 122, no. 5, pp. 478-487, 2010.

[22] R. R. Hamad, M. J. Eriksson, A. Silveira, A. Hamsten, and K. Bremme, "Decreased flow-mediated dilation is present 1 year after a pre-eclamptic pregnancy," Journal of Hypertension, vol. 25, no. 11, pp. 2301-2307, 2007.

[23] A. M. Germain, M. C. Romanik, I. Guerra et al., "Endothelial dysfunction: a link among preeclampsia, recurrent pregnancy loss, and future cardiovascular events?" Hypertension, vol. 49, no. 1, pp. 90-95, 2007.

[24] J. C. Chambers, L. Fusi, I. S. Malik, D. O. Haskard, M. De Swiet, and J. S. Kooner, "Association of maternal endothelial dysfunction with preeclampsia," Journal of the American Medical Association, vol. 285, no. 12, pp. 1607-1612, 2001.

[25] T. Lommerse, R. Aardenburg, A. Houben, and L. L. Peeters, "Endothelium-dependent vasodilatation in formerly preeclamptic women correlates inversely with body mass index and varies independently of plasma volume," Reproductive Sciences, vol. 14, no. 8, pp. 765-770, 2007.
[26] P. K. Agatisa, R. B. Ness, J. M. Roberts, J. P. Costantino, L. H. Kuller, and M. K. McLaughlin, "Impairment of endothelial function in women with a history of preeclampsia: an indicator of cardiovascular risk," American Journal of PhysiologyHeart and Circulatory Physiology, vol. 286, no. 4, pp. H1389H1393, 2004.

[27] A. S. Kvehaugen, R. Dechend, H. B. Ramstad, R. Troisi, D. Fugelseth, and A. C. Staff, "Endothelial function and circulating biomarkers are disturbed in women and children after preeclampsia," Hypertension, vol. 58, no. 1, pp. 63-69, 2011.

[28] F. Khan, J. J. F. Belch, M. MacLeod, and G. Mires, "Changes in endothelial function precede the clinical disease in women in whom preeclampsia develops," Hypertension, vol. 46, no. 5, pp. 1123-1128, 2005.

[29] J. Blaauw, R. Graaff, M. G. van Pampus et al., "Abnormal endothelium-dependent microvascular reactivity in recently preeclamptic women," Obstetrics and Gynecology, vol. 105, no. 3, pp. 626-632, 2005.

[30] J. E. Ramsay, F. Stewart, I. A. Greer, and N. Sattar, "Microvascular dysfunction: a link between pre-eclampsia and maternal coronary heart disease," British Journal of Obstetrics and Gynaecology, vol. 110, no. 11, pp. 1029-1031, 2003.

[31] E. A. P. Steegers, P. von Dadelszen, J. J. Duvekot, and R. Pijnenborg, "Pre-eclampsia," The Lancet, vol. 376, no. 9741, pp. 631-644, 2010.

[32] C. W. G. Redman and I. L. Sargent, "Immunology of preeclampsia," American Journal of Reproductive Immunology, vol. 63, no. 6, pp. 534-543, 2010.

[33] C. W. G. Redman and I. L. Sargent, "Placental stress and preeclampsia: a revised view," Placenta, vol. 30, supplement 1, pp. 38-42, 2009.

[34] V. A. Rodie, D. J. Freeman, N. Sattar, and I. A. Greer, "Preeclampsia and cardiovascular disease: metabolic syndrome of pregnancy?" Atherosclerosis, vol. 175, no. 2, pp. 189-202, 2004.

[35] L. Poston, "Endothelial dysfunction in pre-eclampsia," Pharmacological Reports, vol. 58, pp. 69-74, 2006.

[36] R. J. Levine, C. Lam, C. Qian et al., "Soluble endoglin and other circulating antiangiogenic factors in preeclampsia," The New England Journal of Medicine, vol. 355, no. 10, pp. 9921005, 2006.

[37] R. J. Levine, S. E. Maynard, C. Qian et al., "Circulating angiogenic factors and the risk of preeclampsia," The New England Journal of Medicine, vol. 350, no. 7, pp. 672-683, 2004.

[38] S. Ahmad and A. Ahmed, "Elevated placental soluble vascular endothelial growth factor receptor-1 inhibits angiogenesis in preeclampsia," Circulation Research, vol. 95, no. 9, pp. 884891, 2004.

[39] A. Wang, S. Rana, and S. A. Karumanchi, "Preeclampsia: the role of angiogenic factors in its pathogenesis," Physiology, vol. 24, no. 3, pp. 147-158, 2009.

[40] E. M. George and J. P. Granger, "Endothelin: key mediator of hypertension in preeclampsia," American Journal of Hypertension, vol. 24, no. 9, pp. 964-969, 2011.

[41] A. Yoshida, S. Nakao, M. Kobayashi, and H. Kobayashi, "Flow-mediated vasodilation and plasma fibronectin levels in preeclampsia," Hypertension, vol. 36, no. 3, pp. 400-404, 2000.

[42] M. D. Savvidou, A. D. Hingorani, D. Tsikas, J. C. Frölich, P. Vallance, and K. H. Nicolaides, "Endothelial dysfunction and raised plasma concentrations of asymmetric dimethylarginine in pregnant women who subsequently develop pre-eclampsia," The Lancet, vol. 361, no. 9368, pp. 1511-1517, 2003.

[43] S. Nishikawa, A. Miyamoto, H. Yamamoto, H. Ohshika, and R. Kudo, "Preeclamptic serum enhances endothelin-converting 
enzyme expression in cultured endothelial cells," American Journal of Hypertension, vol. 14, no. 1, pp. 77-83, 2001.

[44] G. A. Knock and L. Poston, "Bradykinin-mediated relaxation of isolated maternal resistance arteries in normal pregnancy and preeclampsia," American Journal of Obstetrics and Gynecology, vol. 175, no. 6, pp. 1668-1674, 1996.

[45] A. P. Cockell and L. Poston, "Flow-mediated vasodilatation is enhanced in normal pregnancy but reduced in preeclampsia," Hypertension, vol. 30, no. 2, pp. 247-251, 1997.

[46] T. Yamamoto, Y. Suzuki, K. Kojima, and K. Suzumori, "Reduced flow-mediated vasodilation is not due to a decrease in production of nitric oxide in preeclampsia," American Journal of Obstetrics and Gynecology, vol. 192, no. 2, pp. 558-563, 2005.

[47] L. Bowyer, M. A. Brown, and M. Jones, "Forearm blood flow in pre-eclampsia," British Journal of Obstetrics and Gynaecology, vol. 110, no. 4, pp. 383-391, 2003.

[48] E. Anastasakis, K. I. Paraskevas, N. Papantoniou et al., "Association between abnormal uterine artery Doppler flow velocimetry, risk of preeclampsia, and indices of arterial structure and function: a pilot study," Angiology, vol. 59, no. 4, pp. 493-499, 2008.

[49] K. M. Hasan, I. T. Manyonda, F. S. Ng, D. R. J. Singer, and T. F. T. Antonios, "Skin capillary density changes in normal pregnancy and pre-eclampsia," Journal of Hypertension, vol. 20, no. 12, pp. 2439-2443, 2002.

[50] B. Sibai, G. Dekker, and M. Kupferminc, "Pre-eclampsia," The Lancet, vol. 365, no. 9461, pp. 785-799, 2005.

[51] L. Poston, A. Briley, P. Seed, F. Kelly, and A. Shennan, "Vitamin $\mathrm{C}$ and vitamin $\mathrm{E}$ in pregnant women at risk for pre-eclampsia (VIP trial): randomised placebo-controlled trial," The Lancet, vol. 367, no. 9517, pp. 1145-1154, 2006.

[52] S. Meher and L. Duley, "Nitric oxide for preventing preeclampsia and its complications," Cochrane Database of Systematic Reviews, no. 2, Article ID CD006490, 2007.

[53] T. F. Luscher, "The endothelium and cardiovascular diseasea complex relation," The New England Journal of Medicine, vol. 330, no. 15, pp. 1081-1083, 1994.

[54] J. P. J. Halcox, W. H. Schenke, G. Zalos et al., "Prognostic value of coronary vascular endothelial dysfunction," Circulation, vol. 106, no. 6, pp. 653-658, 2002.

[55] J. A. Suwaidi, S. Hamasaki, S. T. Higano, R. A. Nishimura, D. R. Holmes, and A. Lerman, "Long-term follow-up of patients with mild coronary artery disease and endothelial dysfunction," Circulation, vol. 101, no. 9, pp. 948-954, 2000.

[56] H. A. Hadi, C. S. Carr, and J. Al Suwaidi, "Endothelial dysfunction: cardiovascular risk factors, therapy, and outcome," Vascular Health and Risk Management, vol. 1, no. 3, pp. 183198, 2005.

[57] C. P. M. Leeson, M. Kattenhorn, R. Morley, A. Lucas, and J. E. Deanfield, "Impact of low birth weight and cardiovascular risk factors on endothelial function in early adult life," Circulation, vol. 103, no. 9, pp. 1264-1268, 2001.

[58] C. M. McEniery, A. Qasem, M. Schmitt, A. P. Avolio, J. R. Cockcroft, and I. B. Wilkinson, "Endothelin-1 regulates arterial pulse wave velocity in vivo," Journal of the American College of Cardiology, vol. 42, no. 11, pp. 1975-1981, 2003.

[59] I. B. Wilkinson, A. Qasem, C. M. McEniery, D. J. Webb, A. P. Avolio, and J. R. Cockcroft, "Nitric oxide regulates local arterial distensibility in vivo," Circulation, vol. 105, no. 2, pp. 213-217, 2002.

[60] C. M. McEniery, S. Wallace, I. S. MacKenzie et al., "Endothelial function is associated with pulse pressure, pulse wave velocity, and augmentation index in healthy humans," Hypertension, vol. 48, no. 4, pp. 602-608, 2006.

[61] J. P. J. Halcox, A. E. Donald, E. Ellins et al., "Endothelial function predicts progression of carotid intima-media thickness," Circulation, vol. 119, no. 7, pp. 1005-1012, 2009.

[62] M. Juonala, J. S. A. Viikari, T. Laitinen et al., "Interrelations between brachial endothelial function and carotid intimamedia thickness in young adults: the Cardiovascular Risk in Young Finns Study," Circulation, vol. 110, no. 18, pp. 29182923, 2004.

[63] P. J. Touboul, M. G. Hennerici, S. Meairs et al., "Mannheim intima-media thickness consensus," Cerebrovascular Diseases, vol. 18, no. 4, pp. 346-349, 2004.

[64] S. Sanada, K. Node, T. Minamino et al., "Long-acting $\mathrm{Ca}^{2+}$ blockers prevent myocardial remodeling induced by chronic NO inhibition in rats," Hypertension, vol. 41, no. 4, pp. 963967, 2003.

[65] L. A. Barouch, R. W. Harrison, M. W. Skaf et al., "Nitric oxide regulates the heart by spatial confinement of nitric oxide synthase isoforms," Nature, vol. 416, no. 6878, pp. 337-339, 2002.

[66] D. Levy, R. J. Garrison, D. D. Savage, W. B. Kannel, and W. P. Castelli, "Prognostic implications of echocardiographically determined left ventricular mass in the Framingham Heart Study," The New England Journal of Medicine, vol. 322, no. 22, pp. 1561-1566, 1990.

[67] F. Perticone, R. Maio, R. Ceravolo, C. Cosco, C. Cloro, and P. L. Mattioli, "Relationship between left ventricular mass and endothelium-dependent vasodilation in never-treated hypertensive patients," Circulation, vol. 99, no. 15, pp. 19911996, 1999.

[68] J. Sung, P. Ouyang, A. C. Bacher et al., "Peripheral endothelium-dependent flow-mediated vasodilatation is associated with left ventricular mass in older persons with hypertension," American Heart Journal, vol. 144, no. 1, pp. 3944, 2002.

[69] V. Palmieri, G. Storto, E. Arezzi et al., "Relations of left ventricular mass and systolic function to endothelial function and coronary flow reserve in healthy, new discovered hypertensive subjects," Journal of Human Hypertension, vol. 19, no. 12, pp. 941-950, 2005.

[70] L. Lind, "Left ventricular mass is related to endotheliumdependent vasodilation in the forearm, but not in the brachial artery, in elderly subjects: the Prospective Investigation of the Vasculature in Uppsala Seniors study," Journal of Human Hypertension, vol. 22, no. 11, pp. 767-773, 2008.

[71] T. Hasegawa, B. Boden-Albala, K. Eguchi et al., "Impaired flow-mediated vasodilatation is associated with increased left ventricular mass in a multiethnic population. the northern manhattan study," American Journal of Hypertension, vol. 23, no. 4, pp. 413-419, 2010.

[72] J. Yeboah, J. R. Crouse, D. A. Bluemke et al., "Endothelial dysfunction is associated with left ventricular mass (assessed using MRI) in an adult population (MESA)," Journal of Human Hypertension, vol. 25, no. 1, pp. 25-31, 2011.

[73] C. Antoniades, S. Mussa, C. Shirodaria et al., "Relation of preoperative radial artery flow-mediated dilatation to nitric oxide bioavailability in radial artery grafts used in off-pump coronary artery bypass grafting," The American Journal of Cardiology, vol. 103, no. 2, pp. 216-220, 2009.

[74] C. Leeson, M. Robinson, J. Francis et al., "Cardiovascular magnetic resonance imaging for non-invasive assessment of vascular function: validation against ultrasound," Journal of 
Cardiovascular Magnetic Resonance, vol. 8, no. 2, pp. 381-387, 2006.

[75] E. M. Urbina, R. V. Williams, B. S. Alpert et al., "Noninvasive assessment of subclinical atherosclerosis in children and adolescents: recommendations for standard assessment for clinical research: a scientific statement from the american heart association," Hypertension, vol. 54, no. 5, pp. 919-950, 2009.

[76] M. W. Lorenz, H. S. Markus, M. L. Bots, M. Rosvall, and M. Sitzer, "Prediction of clinical cardiovascular events with carotid intima-media thickness: a systematic review and meta-analysis," Circulation, vol. 115, no. 4, pp. 459-467, 2007.

[77] G. Ajne, K. Wolff, F. Fyhrquist, K. Carlström, A. HemsénMörtberg, and H. Nisell, "Endothelin converting enzyme (ECE) activity in normal pregnancy and preeclampsia," Hypertension in Pregnancy, vol. 22, no. 3, pp. 215-224, 2003.

[78] F. M. Stewart, D. J. Freeman, J. E. Ramsay, I. A. Greer, M. Caslake, and W. R. Ferrell, "Longitudinal assessment of maternal endothelial function and markers of inflammation and placental function throughout pregnancy in lean and obese mothers," Journal of Clinical Endocrinology and Metabolism, vol. 92, no. 3, pp. 969-975, 2007.

[79] D. J. Freeman, F. McManus, E. A. Brown et al., "Short- and long-term changes in plasma inflammatory markers associated with preeclampsia," Hypertension, vol. 44, no. 5, pp. 708-714, 2004.

[80] N. Sattar, J. Ramsay, L. Crawford, H. Cheyne, and I. A. Greer, "Classic and novel risk factor parameters in women with a history of preeclampsia," Hypertension, vol. 42, no. 1, pp. 39 42, 2003.

[81] A. J. H. M. Houben, P. W. De Leeuw, and L. L. H. Peeters, "Configuration of the microcirculation in pre-eclampsia: possible role of the venular system," Journal of Hypertension, vol. 25, no. 8, pp. 1665-1670, 2007.

[82] E. Kajantie, J. G. Eriksson, C. Osmond, K. Thornburg, and D. J. P. Barker, "Pre-eclampsia is associated with increased risk of stroke in the adult offspring the helsinki birth cohort study," Stroke, vol. 40, no. 4, pp. 1176-1180, 2009.

[83] K. Palmsten, S. L. Buka, and K. B. Michels, "Maternal pregnancy-related hypertension and risk for hypertension in offspring later in life," Obstetrics and Gynecology, vol. 116, no. 4, pp. 858-864, 2010.

[84] I. Ferreira, L. L. Peeters, and C. D. A. Stehouwer, "Preeclampsia and increased blood pressure in the offspring: meta-analysis and critical review of the evidence," Journal of Hypertension, vol. 27, no. 10, pp. 1955-1959, 2009.

[85] NICE, "Hypertension (Update)," 2011, http://www.nice.org. uk/newsroom/pressreleases/NewGuidelineForDiagnosingAnd TreatingHighBloodPressure.jsp.

[86] M. Akcakus, L. Altunay, A. Yikilmaz, C. Yazici, and E. Koklu, "The relationship between abdominal aortic intima-media thickness and lipid profile in neonates born to mothers with preeclampsia," Journal of Pediatric Endocrinology and Metabolism, vol. 23, no. 11, pp. 1143-1149, 2010.

[87] P. Y. Jayet, S. F. Rimoldi, T. Stuber et al., "Pulmonary and systemic vascular dysfunction in young offspring of mothers with preeclampsia," Circulation, vol. 122, no. 5, pp. 488-494, 2010.

[88] C. P. M. Leeson, P. H. Whincup, D. G. Cook et al., "Flowmediated dilation in 9- to 11-year-old children: the influence of intrauterine and childhood factors," Circulation, vol. 96, no. 7, pp. 2233-2238, 1997.
[89] A. L. Fowden, D. A. Giussani, and A. J. Forhead, "Intrauterine programming of physiological systems: causes and consequences," Physiology, vol. 21, no. 1, pp. 29-37, 2006.

[90] C. Catarino, I. Rebelo, L. Belo et al., "Fetal and maternal angiogenic/anti-angiogenic factors in normal and preeclamptic pregnancy," Growth Factors, vol. 27, no. 6, pp. 345-351, 2009.

[91] K. Braekke, P. M. Ueland, N. K. Harsem, and A. C. Staff, "Asymmetric dimethylarginine in the maternal and fetal circulation in preeclampsia Fetal and maternal angiogenic/antiangiogenic factors in normal and preeclamptic pregnancy," Pediatric Research, vol. 66, no. 4, pp. 411-415, 2009.

[92] P. Leeson, "Pediatric prevention of atherosclerosis: targeting early variation in vascular biology," Pediatrics, vol. 119, no. 6, pp. 1204-1206, 2007. 


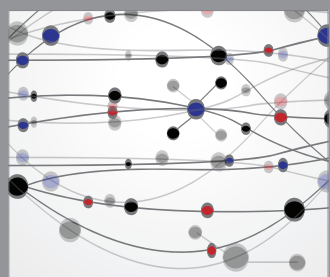

The Scientific World Journal
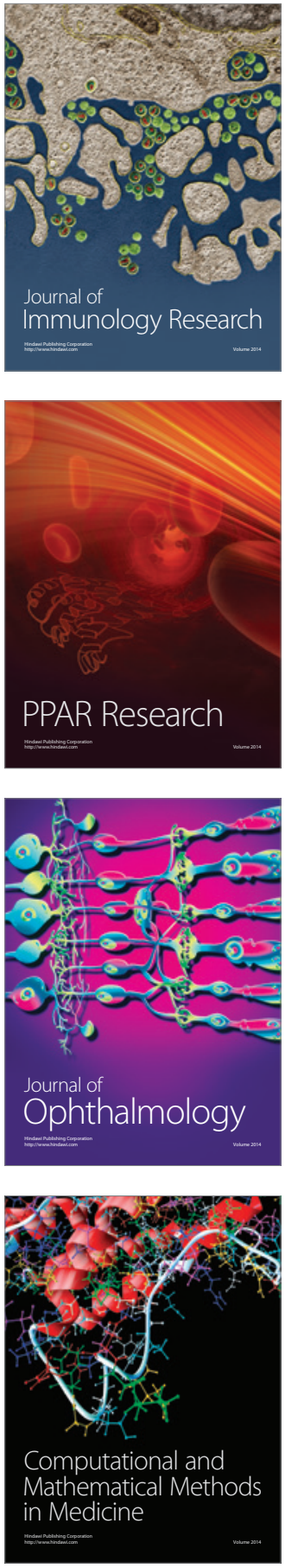

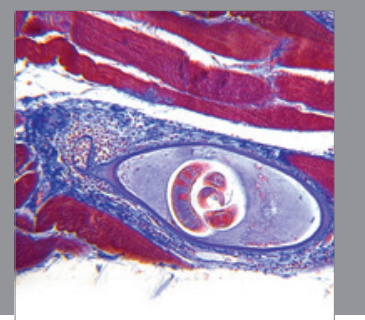

Gastroenterology

Research and Practice
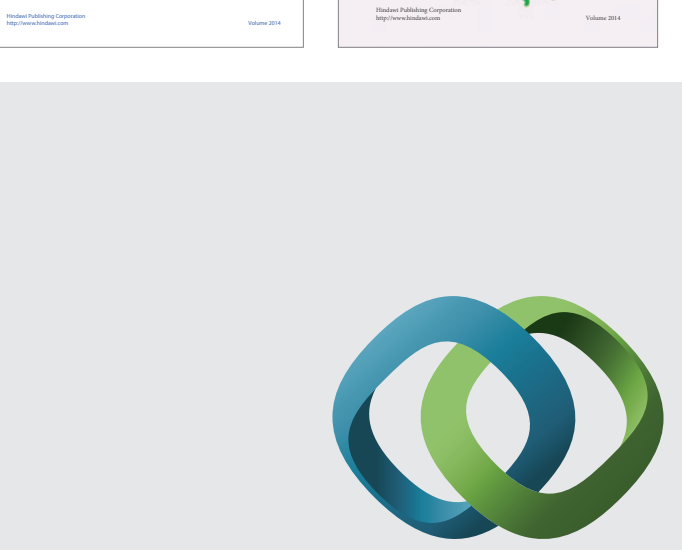

\section{Hindawi}

Submit your manuscripts at

http://www.hindawi.com
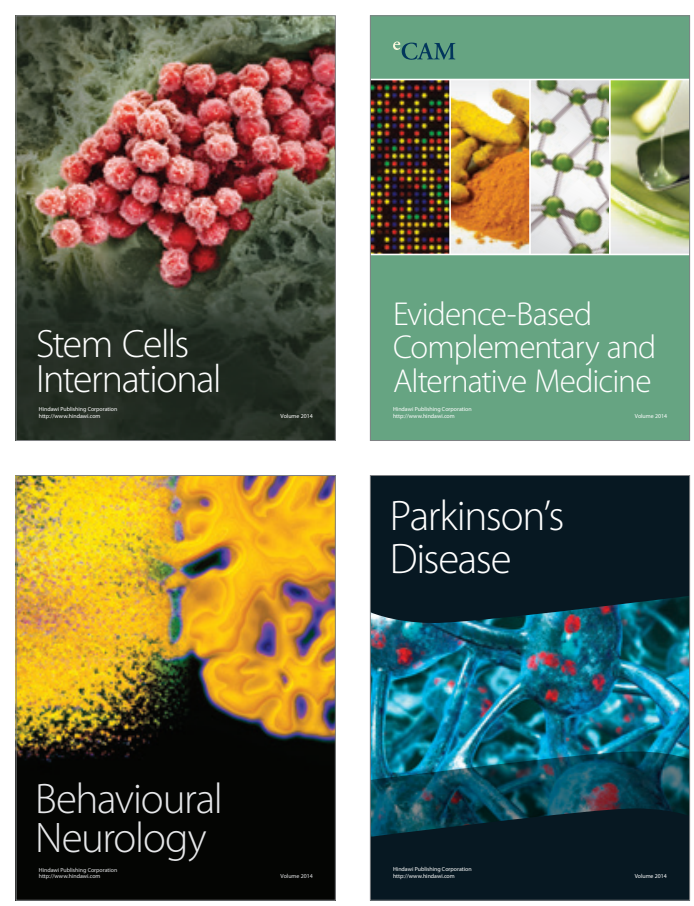

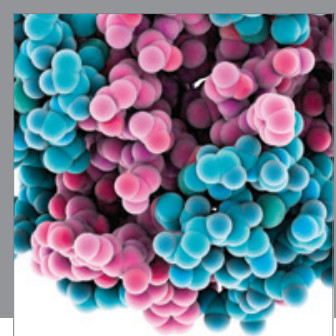

Journal of
Diabetes Research

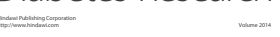

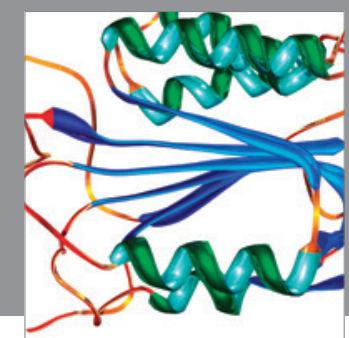

Disease Markers
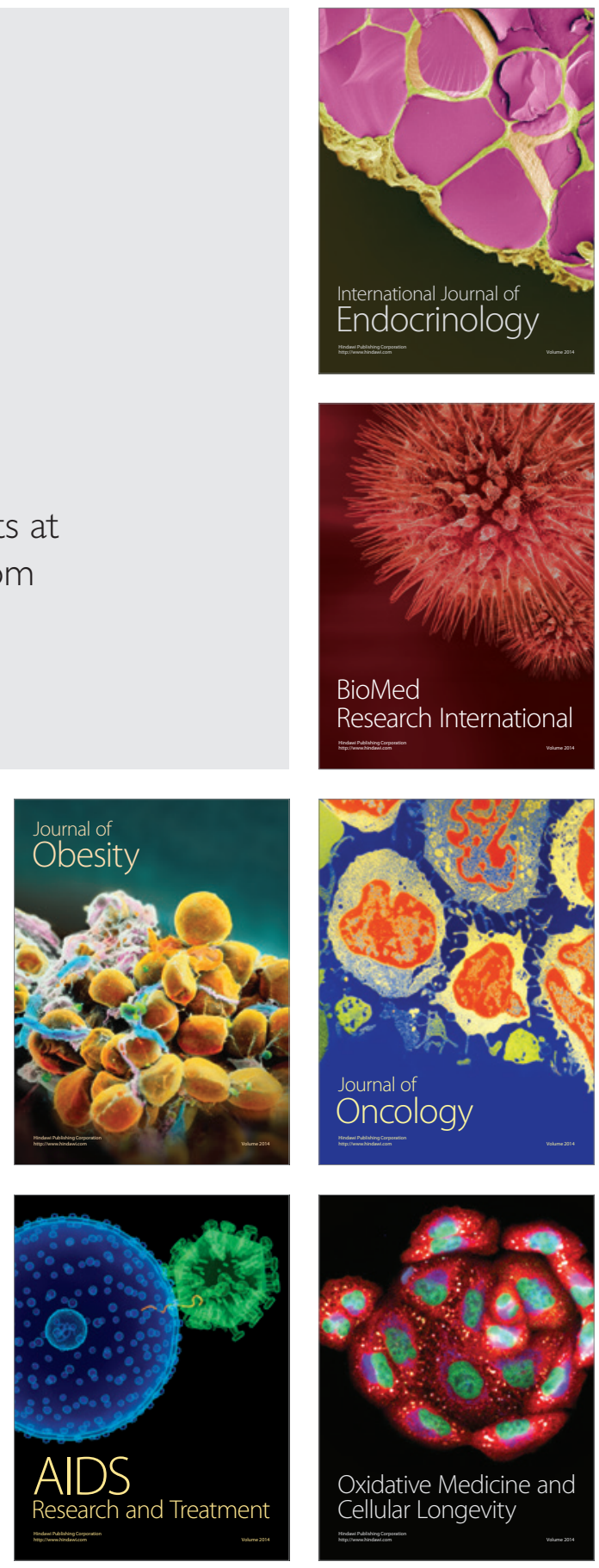